\title{
Marketed under Conditional Approval of New Animal Drug Application
}

National Cancer Institute

\section{Source}

National Cancer Institute. Marketed under Conditional Approval of New Animal Drug

Application. NCI Thesaurus. Code C73588.

A category specifying that a product is marketed under a conditional approval of a New Animal Drug Application. 